\title{
Considerations in using linkage analysis as a presymptomatic test for Huntington's disease
}

\author{
LINDSAY A FARRER*†‡, RICHARD H MYERS* \\ L ADRIENNE CUPPLES $\$$, AND P MICHAEL CONNEALLY \\ From * the Department of Neurology, and + School of Public Health, Boston University School of Medicine, \\ Boston, MA 02118; ¥the Department of Neurology, Harvard University Medical School, Boston, MA 02114; \\ and \$the Department of Medical Genetics, Indiana University School of Medicine, Indianapolis, IN 46223, \\ USA.
}

SUMmaRY The polymorphic locus $D 4 S 10$ that is genetically linked to the locus for Huntington's disease (HD) has made possible a presymptomatic test for those at risk. Because the symptoms of this progressively debilitating and fatal illness are not usually manifest until adulthood, the outcome of the test will influence major decisions about career, marriage, and procreation. Several differential diagnoses must be considered before using the test if HD is not confirmed in at least one family member. Review of a large number of pedigrees has shown that $40 \%$ of persons at risk do not have appropriate family structure for a linkage test. Furthermore, uncooperative or inaccessible relatives may make this test infeasible for many others who wish to be tested. Linkage phase, which must be known in the affected parent for an informative test, can be determined using one or more of 12 probe-enzyme combinations for $D 4 S 10$. Although the polymorphism information content (PIC) value for any one RFLP is less than $40 \%$, the PIC value for the haplotype of the two G8 HindIII, pK083 EcoRI, and R7 BglII RFLPs is greater than $88 \%$. We have developed a scheme to incorporate linkage data and age at onset information adjusted for censored observations, sex of affected parent, and familial correlation for age at onset, using the computer program MLINK for calculation of risk of having HD. Simulated experiments showed that proper age at onset adjustment is crucial to the calculation of the probability of risk. A formal presymptomatic testing protocol, including pre- and post-test counselling, psychological testing, and paternity testing is recommended. Many of these considerations are illustrated in several actual test cases.

The advent of recombinant DNA technology has made possible presymptomatic and prenatal detection of many inherited disorders, including Huntington's disease (HD), ${ }^{1-3}$ by using linked genetic markers (restriction fragment length polymorphisms, RFLPs). ${ }^{4}$ In the absence of a cure or even effective therapeutic intervention, the test places a tremendous emotional burden on the persons being tested and their families 256 and poses several legal and ethical dilemmas for society at large. ${ }^{7-13}$ Clinical trials are in progress in several medical centres to assess the impact of presymptomatic testing of HD in a carefully selected and monitored group of subjects. The HD testing protocol implemented by a multidisciplinary group of geneticists, neurologists,

Received for publication 29 September 1987

Revised version accepted for publication 18 December 1987 psychiatrists, social workers, and molecular biologists at the Huntington Disease Center Without Walls in the Massachusetts General Hospital requires documentation of the diagnosis in at least one family member and extensive evaluation of the subject's psychiatric history, social supports, and pedigree for linkage analysis. Details of the protocol and preliminary findings are reported elsewhere. ${ }^{14}$

Despite the harmful effects that a positive test result might provoke, most notably suicide or suicidal feelings, ${ }^{8}{ }^{15-17}$ the demand for the test among well informed persons at risk for $\mathrm{HD}^{9}{ }^{18-20}$ has convinced a number of medical professionals to implement the test. It is the purpose of this paper to review practical and statistical considerations for presymptomatic testing in HD. Simulated and real examples are provided to support our thesis that an accurate and efficient testing programme requires 
an integrated knowledge of the intricacies of linkage analysis and of clinical and genetic patterns of HD. Many of these factors are relevant considerations for predictive testing in other inherited conditions.

\section{Considerations}

\section{ACCURATE DIAGNOSIS}

A definite diagnosis of HD in at least one close relative is essential before considering any predictive test in a person at risk. Those families with a single case of clinically diagnosed HD are advised to seek a neuropathological confirmation of the diagnosis upon the death of the patient. Currently, clinical examination in conjunction with diagnostic aids, including magnetic resonance imaging (MRI) and computerised tomography (CT scans), are the only methods available for diagnosing HD in living patients. ${ }^{21}$ Generally, persons who present with chorea are more likely to be diagnosed early and correctly whereas the diagnosis cannot be made confidently in persons whose only symptoms are psychiatric, and these patients are more likely to receive only a psychiatric diagnosis initially. The range in clinical expression thus makes the confirmation of a family history an essential prerequisite for the diagnosis.

A recent study of all HD patients living in Maryland showed that $15 \%(31 / 212)$ reported as having HD had been misdiagnosed and had other neurological disorders. ${ }^{22}$ In a suspicious case of HD, a number of differential diagnoses, particularly other causes of inherited chorea and dementia, should be considered. Cerebellar ataxia, familial Alzheimer's disease, Wilson's disease, choreoacanthocytosis, and Creutzfeldt-Jakob disease can be ruled out by the appropriate tests. The differentiation between HD and tardive dyskinesia may be extremely difficult; however, the latter disorder has some unique motor abnormalities (for details, see Hayden $\left.^{2.3}\right)$. Also, the symptoms in late stage HD are very similar to those in Parkinson's disease..$^{23}$ Other disorders which may mimic HD (phenocopies) are usually distinguished by their non-progressive nature or lack of family history.

It is essential that every family member who provides a blood sample in the linkage test is neurologically evaluated to establish presence or absence of HD. Failure to assign HD phenotype correctly (that is, affected or unaffected) to any person whose DNA is examined or marker phenotypes inferred in the linkage analysis will result in an inaccurate or perhaps erroneous result.

FAMILY STRUCTURE

An informative test result can be obtained only if the test subject has a sufficient number of relatives $\stackrel{\mathbb{D}}{\rightarrow}$ from a family structure from which parental phase of $\vec{\Rightarrow}$ alleles at the HD locus with alleles at the linkage $\stackrel{5}{+}$ marker loci can be deduced. In this context the term phase refers to the orientation of marker alleles and HD alleles (that is, HD or wild type) on the $\frac{\text { क }}{\vec{D}}$ homologous chromosome pair. The determination $\mathbb{Q}$ of phase requires a family structure with living members in at least two generations and at least one $\vec{\circ}$ affected relative closely related to the test subject. If the living affected relative is more distantly related, $\vec{\omega}$ it is often possible to establish partial phase which may be sufficient if the relative and test subject share a rare haplotype. Unaffected sibs, unless they is are elderly, provide little information about phase 0 because the expression of HD usually occurs in mid if or late life. Consequently, a sample from at least $\forall$ one affected relative must be studied. We analysed $ᄋ$ the structure of families with HD whose genealogies were contributed to the Huntington Disease Re- $c$ s search Roster at Indiana University before 1984 to $\frac{\mathbb{D}}{O}$ determine in what proportion a genetic prediction $\mathbb{D}$ could be achieved for a person at risk or a pregnancy $\overline{0}$ of that person. A total of 3533 subjects at risk between the ages of 18 and 65 years were classified $\vec{\varphi}$ into 16 distinct family structures (fig 1).

Three generation data including the affecte parent and the affected grandparent contribute th most information to the determination of linkage phase. Although this family structure is the most desirable, it is one of the least frequently observed $\frac{\otimes}{\varnothing}$ situations among persons who are at risk for HD, $\varrho$ accounting for $1.9 \%$ of family structures (fig 1). In $\overrightarrow{\overrightarrow{0}}$ fact, fewer than $14 \%$ of all persons at risk have the affected parent and either grandparent available for study (table 1). This percentage is remarkably similar to an estimate derived from a British family sample. ${ }^{24}$ At the other extreme, predictive testing using linkage analysis is not possible for more than one-fifth of the at risk HD population because there are no living affected relatives. Furthermore, it is unlikely that the family structure will allow an

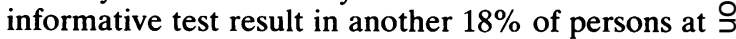
risk (fig 1 , pedigrees $8,12,13$, and 14) because $D$ linkage phase in the affected parent cannot be determined with confidence. Thus, predictive test- N ing using linkage analysis is not a feasible option for approximately $40 \%$ of persons who may want to know whether or not they carry the HD gene. In $\mathrm{\omega}$ contrast, table 1 shows that at least $39 \%$ of these cases could use the test for prediction in a fetus or 0 offspring because the affected parent is living. Such $\overparen{\varnothing}$ testing would also be informative for many cases in $\stackrel{\mathcal{C}}{+}$ which the spouse of the affected parent is living. In 0 the future, a higher proportion of subjects at risk will have an informative family structure because of 


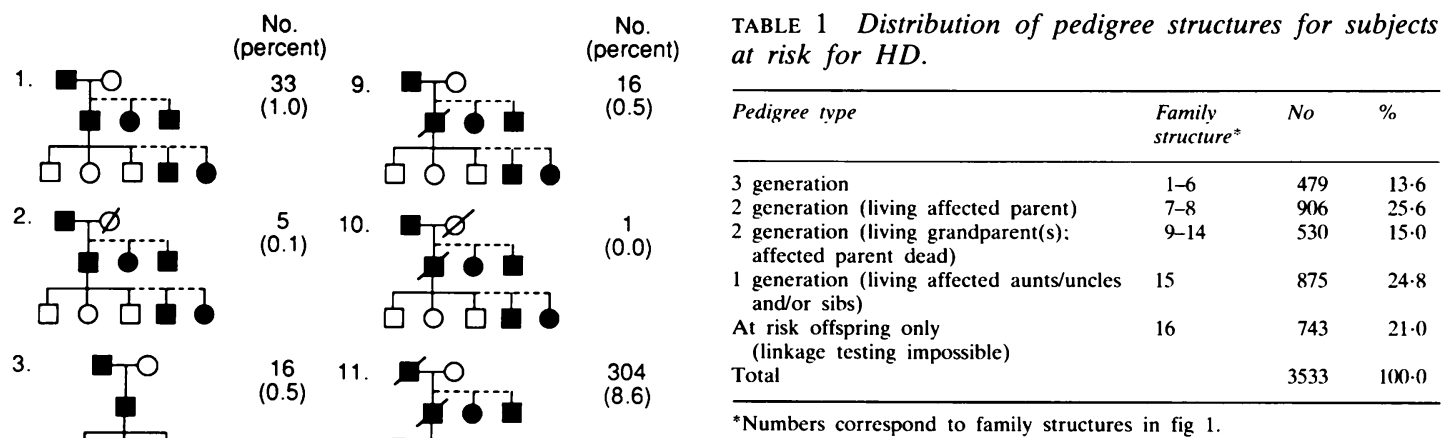

4.

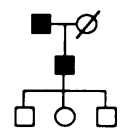

5.

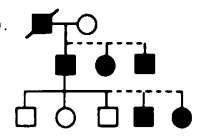

6

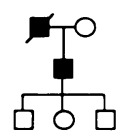

7

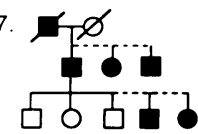

8

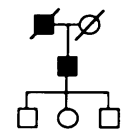

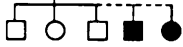

10
$(0.3)$

12.

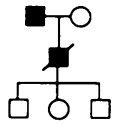

225
$(6.4)$

13.

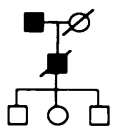

$190 \quad 14$

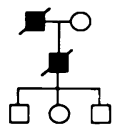

475

(13.4)

15.
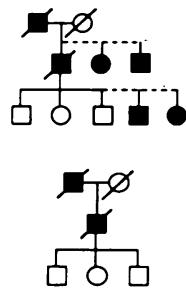

431
12.2
743

(21.0)

9
$(0.3)$

$(0.1)$

198

(5.6)

875

(25.8)

3533
$(100)$ generation (living grandparent(s):

$9-14 \quad 530 \quad 15 \cdot 0$
14

and/or sibs)

At risk offspring only
(linkage testing impossible)

*Numbers correspond to family structures in fig 1 .

blood samples were unavailable from members whose genetic information is crucial to the linkage analysis. The proportion of relatives who refuse to cooperate has not been determined. In our testing experience $^{14}$ only one relative with a highly desired sample has refused to donate a blood sample in the families of the first 18 persons at risk seeking a test. More than 80 blood samples have been collected without obligation. HD has a tendency, however, to disrupt and disintegrate social networks because of economic hardship, stigma, denial, and guilt. It is not advisable and is usually not feasible for the health professional who is administering the test to solicit participation from relatives. Thus, the perhaps emotionally distressed test subject has the additional responsibility of contacting and persuading relatives, some of whom he or she may never have met, to donate a blood sample and consent to a neurological examination. Although the health professional may provide a follow up letter explaining the purpose of the neurological examination and blood sample, he or she should avoid the role of
16.

Total

FIG 1 Family structures for subjects at risk for $H D$. Structures are listed in order of informativeness for linkage $(I=$ most informative). Solid lines connect subjects comprising basic type of that family structure; dotted sibship lines imply that at least one affected sib or aunt/uncle is available for study. Dark symbol denotes $H D$; slash through symbol means subject is dead; persons are assumed to be living unless indicated by slash through symbol.

DNA banking (see below). The method for using linkage analysis for fetal testing is presented elsewhere ${ }^{24-27}$ and is discussed later in this paper.

AVAILABILITY OF TISSUE SAMPLES FROM RELATIVES

Even if the family structure is suitable for a presymptomatic test, it would be of little value if arbiter between the resistant relative and the test subject. The possibility of arranging for a neurological examination, the results of which need not be divulged to the person examined, may be an option.

Arrangements should be made to store blood samples from critical relatives of persons at risk who wish to defer testing and from persons who are considered too young for testing, to ensure that genetic information will be available from persons who may die before the test is used. Conneally et $a^{25}$ advocate banking DNA from late stage HD patients, elderly unaffected parents of affected persons, elderly unaffected aunts and uncles, and other important relatives in fragile health. A national blood sample storage programme has been established by Dr Conneally at Indiana University.

NUMBER AND RELATIVE POSITIONS OF MARKER

LOCI AROUND THE HD LOCUS

Knowledge of the organisation and properties of the 
region of the genetic map encompassing the HD gene is tantamount to a proper linkage analysis. There is a paucity of genetic markers localised to the tip of the short arm of chromosome 4 and until recently only one polymorphic marker $(D 4 S 10)$ was close enough to the HD locus to be useful for linkage. $D 4 S 10$ was mapped to this region by a series of experiments using chromosomal deletions from Wolf-Hirschhorn patients ${ }^{28}$ and by in situ hybridisation. ${ }^{29}{ }^{30} \mathrm{HD}$ was assigned to this region by inference because of linkage to $D 4 S 10 .{ }^{1}$ The maximum likelihood estimate of recombination, $\theta$, between the HD locus and $D 4 S 10$ is $0 \cdot 04$ (equivalent to $4 \mathrm{cM}$ ) with a one lod score unit support interval of 0.024 to $0.065 .^{31}$ Thus, the maximum level of accuracy for a predictive test result using only the D4S10 RFLPs is $96 \%$; there is a $4 \%$ chance that a recombinant event occurred in the gamete from the affected parent so that the linkage phase in the asymptomatic offspring is the reverse of that in the parent. Multipoint linkage analysis using chromosome 4 markers proximal to $D 4 S 10$ has established that the HD gene is located closer to the telomere than $D 4 S 10 .{ }^{32}$ Recently, several other highly polymorphic markers have been identified that map near the HD locus including $D 4 S 43,{ }^{32} D 4 S 62,{ }^{27}$ and $D 4 S 95 .^{33} D 4 S 62$ lies closer to the centromere than $D 4 S 10 .^{34}$ Since no crossovers between $H D$ and D4S43 have been observed, it is unclear whether this marker is distal to the HD locus. ${ }^{32}$ Preliminary evidence suggests that $D 4 S 95$ is also closer to and on

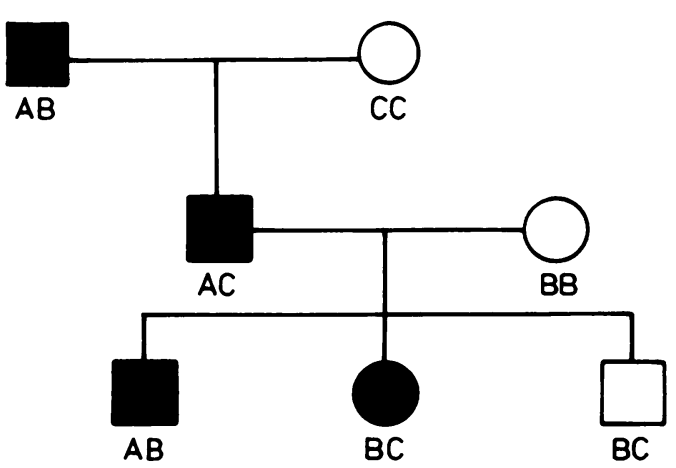

FIG 2 Pedigree showing an obligate crossover between $H D$ and D4S10. Phenotypes for D4S10 are given under symbol for subject. Parental linkage phase is known because genetic information from the grandparents was available. Thus, the affected girl is a recombinant. Without knowing the grandparental phenotypes for D4S10, it is equally likely that she or her brother inherited the recombinant chromosome 4 from the father. In the latter case, the linkage test would be uninformative for the unaffected brother.
TABLE 2 RFLPs at the D4S10 locus.

\begin{tabular}{|c|c|c|c|c|c|c|}
\hline $\begin{array}{l}\text { Probe } \\
\text { name }\end{array}$ & Enzyme & Allele & $\begin{array}{l}\text { Variable } \\
\text { band length }\end{array}$ & Frequency & PIC & Reference \\
\hline \multirow[t]{4}{*}{ G8,pK082 } & HindIII & $\mathrm{A} 1$ & 17.5 & 0.79 & 0.28 & 1 \\
\hline & & A2 & $15 \cdot 0$ & 0.21 & & \\
\hline & & B1 & $3.7,1.2 \dagger$ & 0.81 & 0.26 & 1 \\
\hline & & B2 & 4.9 & 0.19 & & \\
\hline \multirow[t]{2}{*}{ pK082 } & PstI & $\mathrm{Cl}$ & $5 \cdot 6$ & 0.92 & $0 \cdot 14$ & 37 \\
\hline & & $\mathrm{C} 2$ & $2 \cdot 4$ & 0.08 & & \\
\hline \multirow[t]{2}{*}{ pK082 } & $B g / I$ & D1 & 3.6 & $0 \cdot 15$ & 0.22 & 37 \\
\hline & & D2 & 2.7 & 0.85 & & \\
\hline \multirow[t]{2}{*}{ pK082 } & $N c i I$ & E1 & 1.6 & 0.77 & 0.29 & 37 \\
\hline & & E2 & 0.7 & 0.23 & & \\
\hline \multirow[t]{2}{*}{ pK082 } & TaqI & $\mathrm{F} 1$ & 3.7 & $0 \cdot 80$ & $0 \cdot 27$ & 37 \\
\hline & & F2 & $2 \cdot 0,1 \cdot 7$ & 0.20 & & \\
\hline \multirow[t]{2}{*}{ pK083 } & EcoRI & G1 & $14 \cdot 0$ & 0.60 & $0 \cdot 36$ & 37 \\
\hline & & G2 & 11.0 & 0.40 & & \\
\hline \multirow[t]{2}{*}{$\mathrm{R} 7^{*}$} & $B g l I$ & $\mathrm{H} 1$ & $2 \cdot 0$ & 0.40 & 0.36 & 37 \\
\hline & & $\mathrm{H} 2$ & 1.9 & 0.50 & & \\
\hline \multirow[t]{2}{*}{ R7* } & $P v u I I$ & I1 & 0.9 & 0.40 & 0.36 & 37 \\
\hline & & 12 & 0.8 & 0.50 & & \\
\hline \multirow[t]{2}{*}{ R7* } & SacI & J1 & 0.9 & $0 \cdot 40$ & $0 \cdot 36$ & 37 \\
\hline & & $\mathrm{J} 2$ & $0 \cdot 8$ & 0.50 & & \\
\hline \multirow[t]{2}{*}{ G8 } & EcoRI & $\mathrm{K} 1$ & $6 \cdot 0$ & 0.96 & $0.07 \ddagger$ & 37 \\
\hline & & K2 & $5 \cdot 5$ & $0 \cdot 04$ & & \\
\hline \multirow[t]{2}{*}{ pTV20 } & $B g I I I$ & L1 & $3 \cdot 5$ & 0.67 & $0 \cdot 34$ & 38 \\
\hline & & $\mathrm{L} 2$ & $2 \cdot 3$ & $0 \cdot 33$ & & \\
\hline
\end{tabular}

*Complete linkage disequilibrium has been noted among the R7 sites (J Gusella, 1987, personal communication). Thus, there is no gain in information when $\mathbf{R} 7$ is typed with more than one restriction enzyme.

tThis band is produced only with the G8 probe.

$\ddagger$ The PIC appears to be greater than this estimate in American blacks.

the same side of the HD gene as D4S10 or is $\overrightarrow{\mathrm{a}}$ flanking marker. ${ }^{33}$

An example of a pedigree with an obligate crossover between $H D$ and $D 4 S 10$ is shown in fig 2 . Since in most cases the family structure is less than $\overrightarrow{\overrightarrow{0}}$ optimal (fig 1 , table 1) or tissue samples may be 3 unavailable from critical relatives, the resultant probability will usually be less than $96 \%$.

The risk estimate may be grossly inaccurate if there is linkage disequilibrium or sex differences in recombination rate. When there is linkage disequilibrium between the disease locus and marker locus, the proportion of informative families is generally expected to increase because the disease gene is strongly associated with a particular marker 윽 allele. ${ }^{35}$ If the associated marker allele is relatively $D$ uncommon, then the accuracy of the test may increase markedly in pedigrees in which inferences N about linkage phase must be made. There is no

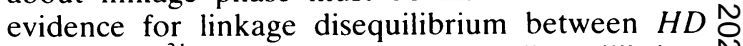
and $D 4 S 10,{ }^{31}$ but there is substantial disequilibrium $N_{\omega}^{N}$ among several restriction sites at $D 4 S 10$ (table 2). In such cases a risk calculation using haplotype fre- 0 quencies calculated from the individual restriction sites is less accurate than one based on empirical $\stackrel{\mathscr{\rho}}{+}$ haplotype frequencies. Farrer et $a l^{36}$ recently ${ }_{0}$ showed that a sex difference in recombination rate profoundly affects the accuracy of a predictive test if 
there is an obligate recombination within the region between the disease locus and the nearest marker locus, or if the distance to the nearest informative between the HD and D4S10 loci. ${ }^{31}$

The informativeness and accuracy of a linkage test for HD would be greatly enhanced if multiple markers flanking the HD locus were available. Having multiple linked marker loci will make a higher proportion of meiotic events informative. Furthermore, multiple crossovers could be detected and counted if the HD locus lies within the cluster of marker loci. Thus, for example, if the HD locus were flanked by two loci each at a distance of $4 \mathrm{cM}$, a fully informative, phase known multipoint linkage test could yield a theoretical probability as high as $99.84 \%$ which corresponds to 1 minus the probability of a double crossover. However, in fact, this probability would be essentially unity because double crossovers almost never occur in regions less than $10 \mathrm{cM}$, owing to interference.
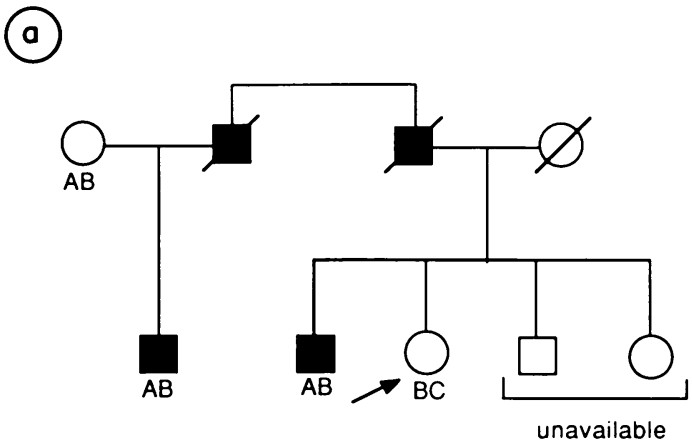

Haplotype Enzyme 1 Enzyme 2

$\begin{array}{lll}A & + & + \\ B & + & - \\ C & - & + \\ D & - & -\end{array}$
marker locus is more than 5 to $10 \mathrm{cM}$. However, only small sex differences have been detected

APPROPRIATE SEGREGATION OF ALLELES AT MARKER LOCI

Even if the family structure is adequate, full cooperation of the family is obtained, and closely linked markers are available, the linkage test will be informative only if there is appropriate segregation of alleles at the marker loci. Minimally, the affected parent must be heterozygous for the marker locus, otherwise it is not possible to determine linkage phase. In the absence of linkage disequilibrium between the HD and D4S10 loci, the a priori probability that an affected subject will be heterozygous for D4S10 depends on the allele frequencies in the general population. Table 2 shows that there are 12 different probe-enzyme combinations which identify RFLPs at D4S10. The polymorphism information content (PIC) ${ }^{4}$ value for any one RFLP is less than $40 \%$, whereas the PIC for the haplotype of the two pK082 HindIII, the pK083 EcoRI, and the R7 BglII RFLPs is greater than $88 \%$. A marker whose PIC value is greater than $50 \%$ is considered to be highly informative for linkage studies. ${ }^{4} D 4 S 43$
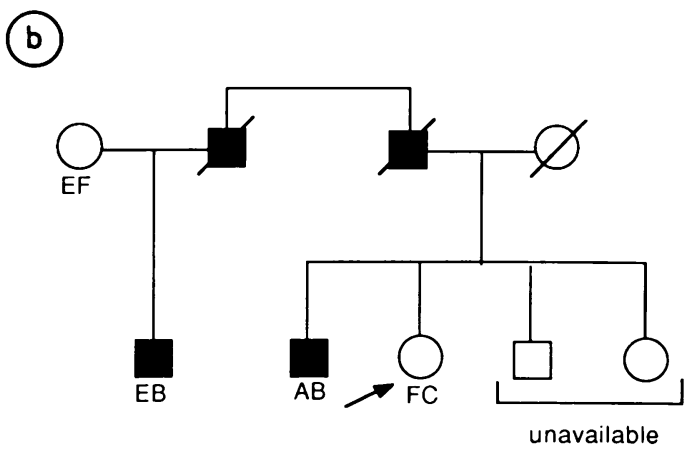

\begin{tabular}{ccrr} 
Haplotype & Enzyme 1 & Enzyme 2 & Enzym \\
\hline A & + & + & + \\
B & + & - & + \\
C & - & + & + \\
D & - & - & + \\
E & + & + & - \\
F & + & - & - \\
G & - & + & - \\
H & - & - & -
\end{tabular}

FIG 3 A frequently encountered family structure for a subject at risk for $H D$ desiring a predictive test. In this example, both parents are dead and two unaffected sibs are unavailable for testing. The haplotype scheme for the hypothetical RFLPS tested is given below the pedigree. Plus and minus signs indicate presence or absence of restriction site. (a) Haplotypes derived from two co-dominant RFLP systems. Since parental linkage phase cannot be determined, this test is uninformative. (b) Haplotypes derived from three co-dominant RFLP systems. Addition of one RFLP system allowed differentiation of chromosomes 4 in the sib pair and assignment of parental linkage phase. 
has a PIC of about $70 \%$ (see reference 32 for complete description of RFLPs).

Nevertheless, key persons may be homozygous for the common RFLPs, as illustrated in fig 3. This frequently encountered example shows that although a pedigree may be informative for $D 4 S 10$, particular segregation patterns can yield uninformative test results, especially if the family structure is less than optimal. One method to resolve this ambiguity involves typing additional RFLPs so that every grandparental chromosome 4 can be distinguished and, thus, linkage phase can be determined (fig 3). The efficacy of this method depends on the PIC of the RFLPs and must be balanced with other demands on the diagnostic laboratory.

\section{AGE DEPENDENT PENETRANCE}

Allowance for age dependent penetrance is critical for presymptomatic testing using linkage analysis in disorders like HD. ${ }^{39}{ }^{40}$ It has been shown ${ }^{41}$ that empirically derived age at onset distributions are inherently biased because they fail to take into account those persons who die from causes unrelated to HD before disease symptoms are manifest, and are thus censored. This approach biases the age at onset distribution downwards and, consequently, results in an underestimate of risk to an asymptomatic person. Cupples $e t a l^{42}$ have recently developed a method to estimate simultaneously the risk of inheriting HD and the age at onset distribution using Kaplan-Meier survival methods. ${ }^{43} \mathrm{We}$ applied this technique using data from the HD Roster, including a group of 622 subjects whose age

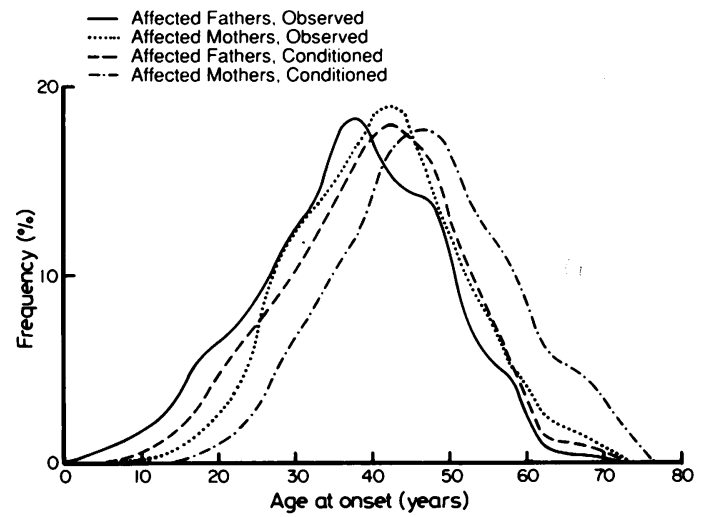

FIG 4 Empirical age at onset distribution for each parental sex ${ }^{14}$ superimposed on the distribution estimated by lifetable analysis (affected fathers, no affected $=315$, no censored $=5310 ;$ affected mothers, no affected $=302$, no censored $=4209$ ). at onset was known and reliably ascertained ${ }^{44}$ and a group of 9602 subjects at risk whose current ages or ages at death (if dead) were known. Persons who are considered possibly to have been affected were excluded from the analysis. The life table adjusted mean (SE) age at onset $(43.5(0.61)$ years) is 5.5 years greater than the observed mean $(38.0(0.44)$ years with a standard deviation of 11.0 years $){ }^{44}$ This difference matches the finding (5.3 years) of Cupples $e t a l^{42}$ in an independent data set and lies within the range ( 4.6 to 7.5 years) obtained by Newcombe. ${ }^{45}$ Separate life table adjusted age at onset distributions derived for offspring of affected males (mean $=41.5(0.77)$ years) and females $($ mean $=45.4(0.89)$ years) are plotted in fig 4 . These means are significantly different $(Z=3.32, p<0.001)$.

The incorporation of conditional information into the linkage analysis makes hand calculations tedious and susceptible to error. ${ }^{2}$ One of the linkage analysis programs that is used for calculating risks, LIPED, ${ }^{46}$ has been modified to incorporate correction for age at onset. ${ }^{47}$ Although the onset correction function in LIPED can be manipulated to take into account familial correlation to age at onset, there is no straightforward method in LIPED to allow for differences in age at onset owing to the se 8 of the affected parent. However, the risk calculation option of the program MLINK from the LINKAGE ${ }^{48}$ package can be used in this manner. Also, with MLINK, genetic information in a family can be maximised by considering the RFLPs as independent sites with $0 \%$ recombination between them when three or fewer systems are analysed. When more than three RFLPs are included in the analysis, haplotypes can be constructed so that the maximum number of marker loci is three. This strategy is most efficacious because it minimises the tedious hand coding of haplotypes, especially when

TABLE 3 Probability of HD gene carrier being affected.

\begin{tabular}{|c|c|c|c|}
\hline \multirow{2}{*}{$\begin{array}{l}\text { Liability } \\
\text { class }\end{array}$} & \multicolumn{2}{|l|}{ Age $(y)$} & \multirow[t]{2}{*}{ Penetrance } \\
\hline & Father affected & Mother affected & \\
\hline Ll & $0-13$ & $0-21$ & 0.010 \\
\hline L2 & $14-20$ & $22-27$ & 0.049 \\
\hline L3 & $21-24$ & $28-29$ & 0.076 \\
\hline L4 & $25-29$ & $30-32$ & $0 \cdot 146$ \\
\hline L5 & $30-34$ & $33-37$ & 0.237 \\
\hline L6 & $35-36$ & $38-39$ & 0.296 \\
\hline L7 & $37-38$ & $40-41$ & 0.377 \\
\hline L8 & $39-41$ & $42-44$ & 0.460 \\
\hline L9 & $42-44$ & $45-46$ & 0.560 \\
\hline L10 & $45-47$ & $47-50$ & 0.677 \\
\hline L11 & $48-49$ & $51-52$ & 0.742 \\
\hline L12 & $50-52$ & $53-55$ & 0.836 \\
\hline L13 & $53-54$ & $56-60$ & 0.919 \\
\hline L14 & $55-59$ & $61-65$ & 0.970 \\
\hline L15 & $60+$ & $66+$ & 0.999 \\
\hline
\end{tabular}


information is available from three or more RFLPs, and it maximises the capabilities of MLINK without placing excessive demands on the computer.

Age dependent penetrance of HD was defined as a step function of liability classes L1 to L15 based on 15 age intervals, corresponding as closely as possible to the survival analysis and sex of parent adjusted distribution for age at onset (table 3). Further adjustment was made to allow for familial clustering of age at onset by assigning a lower or higher liability class if the mean age at onset among affected persons in the kindred was at least $1 / 2 \mathrm{SD}$ (of the family means for age at onset) unit above or below the observed mean age at onset for the HD population. The formula for the adjustment is:

$$
\mathrm{L}_{\mathrm{n}}=\mathrm{L}_{\mathrm{i}}+\mathrm{x}
$$

where $\mathrm{L}_{\mathrm{i}}=\mathrm{i}^{\text {th }}$ liability class for test subject based on current age and adjusted for sex of affected parent

$$
\begin{aligned}
& \mathrm{x}=\text { number of liability classes to be added } \\
& =2 \quad\left[\left(\text { mean } \text { onset }_{\text {pop }}-\text { mean } \text { onset }_{\text {fam }}\right) /\right. \\
& \text { (std. onset } \left.\text { fam means }_{\text {f }}\right] \\
& =2\left[\left(38 \cdot 0-\text { mean onset } \text { fam }_{\text {m }}\right) / 12 \cdot 7\right] \\
& \mathrm{L}_{\mathrm{n}}=\text { new liability class, } \mathrm{n} \text {, after adjustment } \\
& \text { for familial clustering for age at onset. }
\end{aligned}
$$

In a family whose mean age at onset is 65 years (that is, approximately $2 \mathrm{SD}$ units greater than the $\mathrm{HD}$ population mean), the adjustment will change the liability class from L10 to L6 for a 47 year old person and from L15 to L11 for a 66 year old person.

Data were simulated for a fictitious pedigree (fig 5) to measure the potential degree of fluctuation in the probability of being an HD gene carrier owing to the sex of affected parent and familial clustering of age at onset. The simulation consisted of six analyses corresponding to combinations of familial onset pattern (early, average, or late) and sex of affected parent. Probabilities of HD genotype were calculated using MLINK. The linkage problem was treated as a four locus analysis in which the two HindIII RFLPs were combined into one locus as described above. Because the mean age at onset in the early and late onset pedigrees was greater than $1 \mathrm{SD}$ unit below and above, respectively, the HD population mean, an adjustment to the liability for the unaffected offspring was made using equation (1) where $x=2$. The results in table 4 show that, especially for persons whose age lies in the middle of the age at onset distribution, adjustment to the age at onset function may substantially influence the probability.

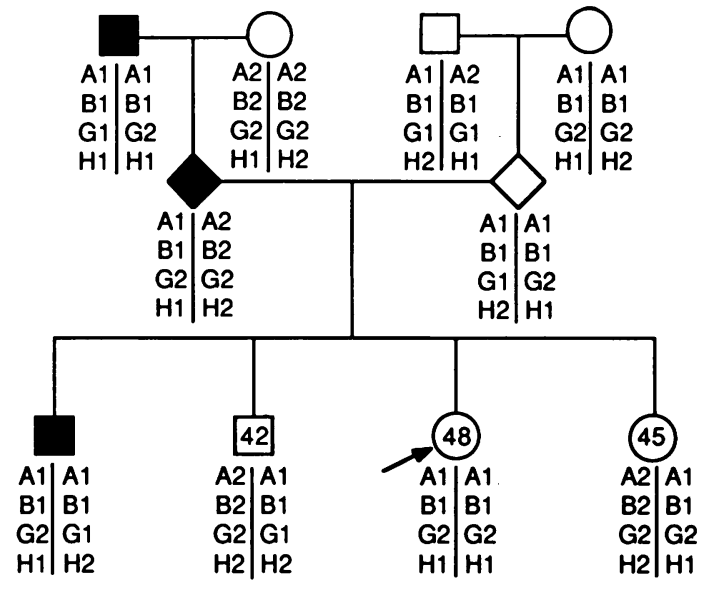

FIG 5 Fictitious pedigree with HD. Diamond shaped symbol indicates that the sex of the person was male or female (see table 4). Ages of the subjects at risk are given inside the pedigree symbols. Consultand is indicated by an arrow. Phenotypes for RFLPs at the D4S10 locus are shown below the pedigree symbols in the descending order HindIII, EcoRI, and BglII. Descriptions of each RFLP system are given in table 2. The extended haplotype includes two HindIII sites but only one is informative in this family. The orientation of alleles on each side of the vertical line represents the most likely linkage phase.

PATERNITY TESTING

Since reported rates of parental exclusion in population studies approximate $5 \%,{ }^{49}$ the possibility of non-paternity should not be overlooked. The discovery of non-paternity in the affected father of a test subject must be handled with extreme caution. Although the child may be relieved to learn that he or she is not at risk for having the disease, emotional trauma evoked by this knowledge may be severe. Non-paternity in the other portions of the pedigree which may have significant consequences on the outcome of the test is difficult to detect unless the extended family is typed.

The need to assure correct paternity must be balanced with economic concerns of performing the presymptomatic test. A large proportion of paternal exclusions could be revealed by typing with $D 4 S 10$ alone if the laboratory types all of the potential variable sites (table 2). However, since some of the restriction enzymes are expensive or hard to work with, it is doubtful that this procedure would be used routinely. Most DNA laboratories are not equipped for or experienced in typing classical marker systems. HLA typing is very expensive and it often requires typing 10 to 15 of the other classical markers to establish paternity, because most of 
TABLE 4 Probability that 48 year old consultand in fig 5 has the gene for $H D$.

\begin{tabular}{lll}
\hline $\begin{array}{l}\text { Familial } \\
\text { mean age } \\
\text { at onset }\end{array}$ & $\begin{array}{l}\text { Father } \\
\text { affected }\end{array}$ & $\begin{array}{l}\text { Mother } \\
\text { affected }\end{array}$ \\
\hline 25 (early) & $0.50(1)^{*}$ & $0.69(2)$ \\
38 (average) & $0.86(3)$ & $0.89(4)$ \\
51 (late) & $0.94(5)$ & $0.94(6)$ \\
\hline
\end{tabular}

Keeping the marker and pedigree information constant (see fig 5). the probability that the consultand is a carrier for HD varies substantially depending upon the familial mean age of onset and sex of the affected parent.

*Liability class $\left(\mathrm{L}_{n}\right)$ for the unaffected offspring in analyses 1 to 6 were derived from table 3 and are as follows.

\begin{tabular}{llll}
\hline Analysis & Consultand & Brother & Sister \\
\hline 1 & L13 & L11 & L.12 \\
2 & L12 & L.10 & L.11 \\
3 & L11 & L9 & L.10 \\
4 & L10 & L8 & L9 \\
5 & L9 & L7 & L8 \\
6 & L8 & L6 & L.5 \\
\hline
\end{tabular}

these systems are not very polymorphic. DNA probes which detect hypervariable sites, such as those used in DNA fingerprinting, ${ }^{50}$ can be used more efficiently.

PSYCHOLOGICAL AND COUNSELLING

CONSIDERATIONS

The ultimate decision to take or not to take the presymptomatic test rests with the person at risk who is facing the threat of developing the disease. The counsellor is responsible for conveying the information which allows the subject to make an informed choice. This includes a presentation of the limitations of the test accuracy as a consequence of genetic recombination. In addition, an estimate of the likelihood that the test will prove informative for the consultand is important, since the possibility of an uninformative test may be substantial if affected persons are not available.

The existing protocol assesses psychological well being as well as available social support mechanisms for those seeking the test. At present, persons who manifest suicidal tendencies or who are under psychiatric care for manic depression or schizophrenia are asked not to take the test. The methods for psychological assessment and counselling are described in greater detail elsewhere. ${ }^{14}$

Prenatal testing is possible with the genetic linkage test for HD. One consideration which some families have raised is that since research in this area is moving so rapidly, perhaps a treatment or cure for the illness might be available in 40 years when a child born now would develop the disease. The ethical dilemmas raised by the prenatal test are perceived quite differently and the decision will depend upon personal perspectives.

Many persons who have requested the presymptomatic test have been diagnosed by subsequent routine neurological evaluation. Because the onset of the disease may be a time of emotional crisis, it is particularly important to make the clinical diagnosis so that medical treatment can be initiated. Therefore, the genetic test programme should include neurological assessment of persons requesting the test.

\section{Examples}

In practice every family structure is unique and relationships among members are unpredictable. The following examples, which represent a composite of several real pedigrees, ${ }^{14}$ emphasise the complexity of predictive testing in HD.

EXAMPLE 1

The initial samples collected and analysed in this pedigree (fig 6) were those from the test subject, his parents, and the unaffected maternal aunt and uncle. Linkage analysis revealed all four grandô parental haplotypes and the inferred phase for the unaffected uncle was $\mathrm{A} 2 / \mathrm{G} 1 / \mathrm{H} 2-\mathrm{A} 2 / \mathrm{G} 2 / \mathrm{H} 1$. Le里 unchallenged, this interpretation would have resulted in designating the consultand as a probable gene carrier. However, the sample from the affected aunt showed that the HD gene is more likely to be segregating with the haplotype $\mathrm{A} 2 / \mathrm{G} 2 / \mathrm{H} 1$ and, barring a crossover event, the unaffected maternal aunt carries the HD gene. Furthermore, phase in the

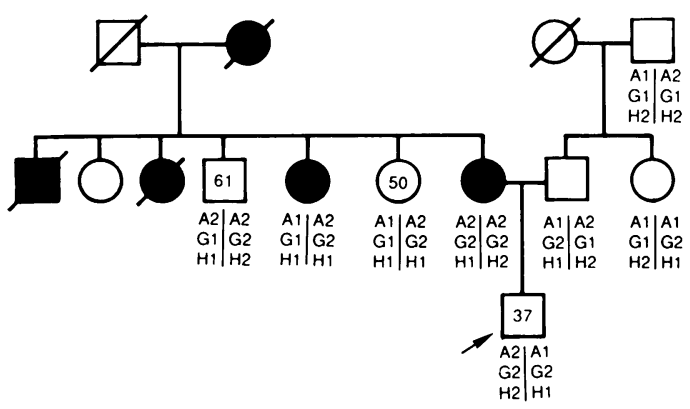

FIG 6 HD pedigree typically encountered for presymptomatic testing. Some aspects of the pedigree structure have been changed to protect the identity of the family. Numbers inside pedigree symbols represent current age. The mean age at onset of the affected persons is 36 years. D4S10 haplotypes are shown below the pedigree symbols in the manner described in fig 5. 
consultand was established as $\mathrm{A} 2 / \mathrm{G} 2 / \mathrm{H} 2-\mathrm{A} 1 / \mathrm{G} 2 / \mathrm{H} 1$ only after additional samples were collected from the paternal grandfather and aunt. Ultimately, it is the paternal aunt who sets phase. Linkage analysis with MLINK using all the information showed that the test subject is most probably not an HD gene carrier (probability $=91 \cdot 7 \%$ ). This example illustrates that analysis of samples from more than one affected relative will lead to a more correct answer and that it is often necessary to analyse samples from relatives of the spouse to derive an informative result.

EXAMPLE 2

This example (fig 7) illustrates the typically encountered situation in which the affected parent is dead. Although it is often possible to reconstruct parental phase from other affected members in the pedigree, in this case the predictive test result is uninformative because the affected parent may be homozygous for D4S10 (carrier probability $=57 \cdot 2 \%$ ). One may be able to increase the informativeness by typing more RFLPs. Suppose the test subject in fig 7 had unaffected sibs. Typing their DNA might reveal that the affected parent is heterozygous for $D 4 S 10$, thus showing that the test subject is probably an HD gene carrier. However, one must resist the temptation to type sibs, who do not wish to know their HD status, sequentially because it may necessarily reveal their diagnosis in order to provide an informative result for the consultand. If all samples are collected and analysed simultaneously, this situation can be averted.

EXAMPLE 3

Fig 8 shows a family in which two consanguineous grandparents have HD. Thus each of the offspring in generation $\mathrm{V}$ are at risk of being a homozygote

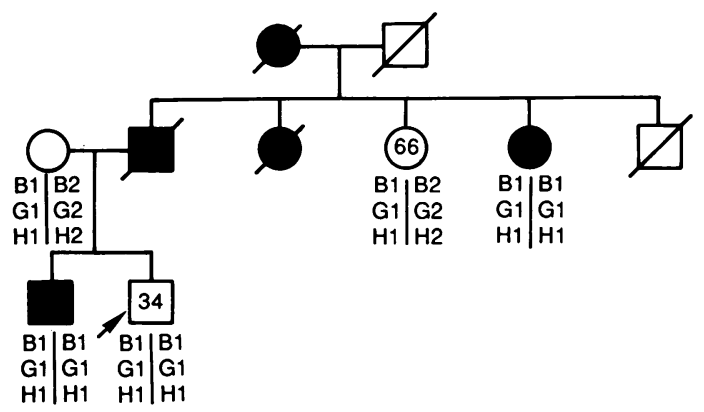

FIG 7 HD pedigree yielded an uninformative test result. The mean age at onset of the illness is 42 years. See fig 5 for explanation of pedigree symbols and marker haplotypes.

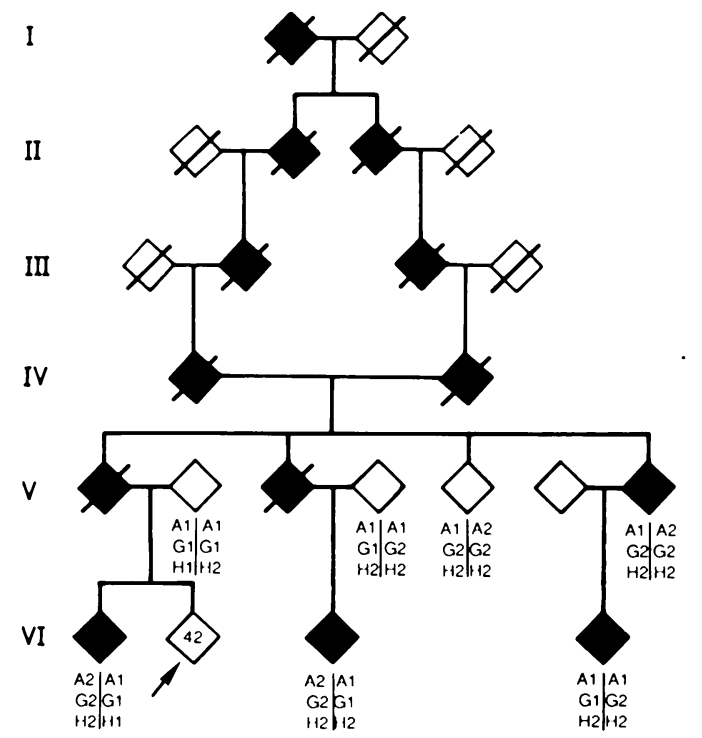

FIG $8 H D$ pedigree with complex family structure. Grandparents of the consultand. VI.2, are second cousins. See fig 5 for explanation of pedigree symbols and marker haplotypes. Sexes are not disclosed to protect the identity of the family. Note that there is at least one crossover between $H D$ and D4S 10 .

for HD. The HD gene in such homozygotes is said to be identical by descent (IBD). The natural history of HD in this family is fairly typical. The mean age at onset is 38 years and no persons experienced an unusually early onset or rapid progression of symptoms. Although one would expect more severe expression in a person homozygous for a dominant disorder, HD is evidently a true Mendelian dominant trait. ${ }^{51}$ At birth, subject VI.2 had a $67 \%$ chance of inheriting at least one mutant HD allele, taking into account the probabilities that subject V.1 is heterozygous or homozygous for $\mathrm{HD}$; the risk increased to $75 \%$ when his sib became affected but has diminished slightly from that because he is unaffected at the age of 42 years.

Linkage analysis showed that there was at least one obligate crossover between $H D$ and D4S10; a minimum of two different haplotypes for $D 4 S 10$ are segregating with HD. Interestingly, subject V.5 is asymptomatic at an advanced age (age not given to protect identity) but has an identical phenotype for D4S10 as sib V.7. Assuming that this person does not have the gene for HD, this linkage phase could have resulted if a crossover occurred between $H D$ and D4S10 in one of his ancestors, or if both IV.1 and IV.2 were homozygous for D4S10. 
The consultand, VI.2, was typed for D4S10, but the phenotype is not disclosed in fig 8 for reasons of confidentiality. Although there are many possibilities for the phenotype, the inferred haplotype inherited from the affected parent was one of the two possessed by V.5 and V.7 (that is $A 1 / \mathrm{G} 2 / \mathrm{H} 2$ or $\mathrm{A} 2 / \mathrm{G} 2 / \mathrm{H} 2$ ). The consultand also inherited the A1/G1/H2 haplotype from the unaffected parent. If subject VI. 2 inherited the $\mathrm{A} 1 / \mathrm{G} 2 / \mathrm{H} 2$ haplotype, he would have a $75 \%$ risk of being a non-carrier, a $25 \%$ risk of being heterozygous for $\mathrm{HD}$, and a $0 \%$ risk of being an HD homozygote. If he inherited the alternative haplotype, the probabilities for being a non-carrier, HD heterozygote, and HD homozygote are $38 \%, 62 \%$, and $0 \%$, respectively. Only the result in the first case is sufficiently different from prior Mendelian expectations to be useful for counselling purposes. Although HD by HD matings are uncommon, there are many more instances of consanguineous unions in which an affected subject has had offspring with a relative at risk for HD.

\section{Conclusions}

Since the discovery of linkage between $H D$ and $D 4 S 10,^{1}$ geneticists have been concerned that presymptomatic testing using the G8 probe would be conducted without conclusive evidence that these two loci are linked in all families. Genetic heterogeneity was suspected on several grounds. First, the disorder is prevalent in many diverse populations, including a few genetic isolates, and it has been assumed that there was no contact between members of these groups. Given the wide variability in symptoms and age at onset, one might assume that the HD phenotype is caused by mutations at more than one locus, as observed in other inherited neurological disorders such as muscular dystrophy and Charcot-Marie-Tooth disease. However, there is now overwhelming evidence that there is only a single locus for HD on chromosome 4 . Conneally ${ }^{52}$ summarised recent epidemiological studies which suggest that the HD mutation, even in genetic isolates, can be traced to emigrants from north western Europe. Moreover, linkage has been documented in phenotypically and racially diverse kindreds. ${ }^{53}$

The genetic linkage test for predicting HD gene carrier status in persons at risk for the disorder is not a routine diagnostic procedure. Because a linkage test requires participation by other family members, many of whom are also at risk, problems of confidentiality, family relationships, diagnosis, and administration are magnified several fold. The anomalous patterns associated with delayed onset of the disorder must be considered in the linkage $\stackrel{\vec{D}}{\rightarrow}$ analysis for the result to be accurate. Proper $\underset{\vec{D}}{\vec{D}}$ adjustment for age at onset is not difficult but in $\stackrel{9}{\frac{9}{9}}$ many cases is not trivial. In most situations the calculation of the probability warrants use of a computer program. Although the marker linked to $H D, D 4 S 10$, is very polymorphic, chance non- $\propto$ segregation of the marker in key portions of a family may yield an uninformative test result. Testing using $\overrightarrow{0}$ new markers ${ }^{32-34}$ will increase the proportion of informative results and the accuracy of results $\vec{\omega}$ overall.

A complete pre-test and post-test counselling protocol is strongly recommended to investigate the is psychological status and support mechanisms for the or consultand and to cushion the impact of the test of result even if it is negative for HD. Arrangements $\forall$ should be made for those persons who will require $\mathrm{O}$ long term psychiatric care. A research protocol for the complete testing programme has been im- $\infty$ plemented and carefully scrutinised. ${ }^{14}$ Despite $\mathbb{D}$ several unanticipated problems in HD testing, it is a $\mathbb{D}$ useful paradigm for others who plan to begin presymptomatic diagnosis of HD.

Finally, the considerations outlined in this paper $\vec{\varphi}$ reflect the current state of affairs in HD. They ab $\infty_{\infty}^{\circ}$ premised on the facts that the HD gene cannot be examined directly and there is neither a cure nof effective treatment for the disease. Our capacity to help persons who are identified as carriers is also limited because this test does not predict whether onset of symptoms will occur in a few months or as $\triangle$ long as several decades in the future. Advances in $\overrightarrow{\overrightarrow{0}}$ molecular genetics and neurochemistry ${ }^{10}$ may make $\exists$ some of these considerations obsolete within several years. One technique, positron emission tomography (PET), shows promise for determining when a presymptomatic HD gene carrier is likely to manifest the disease. In two independent studies it was observed using PET and [18F]fluorodeoxyglucose that symptomatic patients in early stages of the disease have reduced glucose metabolism in the caudate nuclei. ${ }^{21}{ }^{54}$ Mazziotta $e t ~ a l^{21}$ also studied a 옥 group of subjects at risk aged 18 to 58 years. They $\rightarrow$ found excellent agreement between the predicted percentage of carriers based on age and sex adjusted $N$ risk estimates and the percentage with metabolic abnormalities of the caudate nuclei detected with $\tilde{O}$ PET. However, a more recent study of subjects at $N_{\omega}$ risk who were evaluated with PET has shown that $\underset{2}{\sigma}$ this technique is at present unreliable for presymp- 6 tomatic carrier detection. ${ }^{55}$ Regardless of this, $\stackrel{\mathbb{\complement}}{\mathbb{C}}$ refinement of this method may prove valuable for $\stackrel{\oplus}{+}$ counselling carriers identified by linkage and for $\underline{0}$ testing hypotheses about the pathophysiology of the disease and treatment. 
This work was supported in part by USPHS grants N01-NS-9-2320 (Research Roster for Huntington Disease Patients and Families) and NS-16367-07S1 (Huntington Disease Center Without Walls), and a grant from the Massachusetts Huntington Disease Association of America. We thank Rudolph Tanzi and Dr James Gusella for their help in constructing table 2 .

\section{References}

1 Gusella JF, Wexler NS, Conneally PM, et al. A polymorphic DNA marker genetically linked to Huntington's disease. Nature 1983;306:234-8.

2 Conneally PM, Wallace MR, Gusella JF, Wexler NS. Huntington disease: estimation of heterozygote status using linked genetic markers. Genet Epidemiol 1984;1:81-8

3 Wexler NS, Conneally PM, Housman D, Gusella JF. A DNA polymorphism for Huntington's disease marks the future. Arch Neurol 1984;42:20-4.

4 Botstein D, White RL, Skolnick M, Davis RW. Construction of a genetic linkage map in man using restriction fragment length polymorphisms. Am J Hum Genet 1980;32:314-31.

5 Bates M. Ethics of provocative test for Huntington's disease. $N$ Engl J Med 1981;304:175.

6 Mastromauro C, Myers RH, Berkman B. Attitudes toward presymptomatic testing in Huntington's disease. Am J Med Genet 1987;26:271-82.

7 Bains W. Legal problems of Huntington's chorea tests. Nature 1986;322:20.

${ }^{8}$ Craufurd DIO, Harris R. Ethics of predictive testing for Huntington's chorea: the need for more information. $\mathrm{Br} \mathrm{Med} \mathrm{J}$ 1986;293:249-51.

9 Kolata G. Genetic screening raises questions for employers and insurers. Science 1986;232:317-9.

10 Martin JB, Gusella JF. Huntington's disease: pathogenesis and management. $N$ Engl J Med 1986;315:1267-76.

1 Lamport AT. Presymptomatic testing for Huntington chorea: ethical and legal issues. Am J Med Genet 1987;26:307-14.

12 Shaw MW. Invited editorial comment. Testing for the Huntington's disease gene: a right to know, a right not to know, or a duty to know. Am J Med Genet 1987;26:243-6.

13 Smurl JF, Weaver DD. Presymptomatic testing for Huntington chorea: guidelines for moral and social accountability. Am J Med Genet 1987;26:247-57.

14 Meissen G, Myers RH, Mastromauro C, et al. Predictive testing in Huntington's disease with use of a linked DNA marker. $N$ Engl J Med 1988;318:535-42.

15 Farrer LA. Suicide and attempted suicide in Huntington disease: implications for preclinical testing of persons at-risk. Am J Med Genet 1986;24:305-12.

16 Farrer LA. Suicide and presymptomatic testing in Huntington disease. Am J Med Genet 1987;26:319-20.

17 Kessler S. The dilemma of suicide and Huntington disease. Am J Med Genet 1987;26:315-7.

${ }^{18}$ Kessler S, Field T, Worth L, Mosbarger H. Attitudes of persons at risk for Huntington disease toward predictive testing. $A m J$ Med Genet 1987;26:259-70.

19 Meissen GJ, Berchek RL. Intended use of predictive testing by those at risk for Huntington disease. Am J Med Genet 1987;26:283-94.

20 Markel DS, Young AB, Penny JB. At-risk person's attitudes toward presymptomatic and prenatal testing of Huntington disease in Michigan. Am J Med Genet 1987;26:295-306.

21 Mazziotta JC, Phelps ME, Pahl JJ, et al. Reduced cerebral glucose metabolism in asymptomatic subjects at risk for Huntington's disease. N Engl J Med 1987;316:357-62.
22 Folstein SE, Leigh RJ, Parhad IM, Folstein MF. The diagnosis of Huntington's disease. Neurology (Minneap) 1986;36:1279-83.

23 Hayden MR. Huntington's chorea. New York: Springer-Verlag, 1981.

24 Harper PS, Sarfarazi M. Genetic prediction and family structure in Huntington's chorea. Br Med J 1985;290:1929-31.

25 Conneally PM, Gusella JF, Wexler NS. Huntington's disease: linkage with G8 on chromsome 4 and its consequences. In: Medical genetics: past, present, future. New York: Alan R Liss, 1985:53-60.

26 Quarrell OWJ, Meredith AL, Tyler A, Youngman S, Upadhyaya $M$, Harper PS. Exclusion testing for Huntington's disease in pregnancy, using a closely linked DNA marker. Lancet 1987;i: 1281-3.

27 Hayden MR, Hewitt J, Kaselein JJP, et al. First-trimester prenatal diagnosis for Huntington's disease with DNA probes. Lancet 1987;i:1284-5.

28 Gusella JF, Tanzi RE, Bader PI, et al. Deletion of the Huntington's disease-linked G8 (D4S10) locus in WolfHirschhorn syndrome. Nature 1985;318:75-8.

29 Magenis RE, Gusella J, Weliky K, et al. Huntington diseaselinked restriction fragment length polymorphism localized within band p16.1 of chromosome 4 by in situ hybridization. $A m J$ Hum Genet 1986;39:383-91.

30) Wang HS, Greenberg CR. Hewitt J, Kalousek D, Hayden MR. Subregional assignment of the marker G8 (D4S10) for Huntington disease to chromosome 4p16.1-16.3. Am J Hum Genet 1986;39:392-6.

31 Haines JL, Tanzi R, Wexler N, et al. No evidence of linkage heterogeneity between Huntington disease (HD) and G8 (D4S10). Am J Hum Genet 1986;39:156A.

32 Gilliam TC, Bucan M, MacDonald ME, et al. A DNA segment encoding two genes very tightly linked to Huntington's disease. Science 1987;238:950-2.

33 Hayden MR, Hewitt J, Wasmuth JJ, et al. A polymorphic DNA marker that represents a conserved expressed sequence in the region of the Huntington disease gene. Am J Hum Genet 1988; 42:125-31.

34 Wasmuth JJ, Hewitt J, Smith B, et al. A highly polymorphic locus very tightly linked to the Huntington's disease gene. Nature 1988;332:734-6.

35. Chakravarti A. Utility and efficiency of linked marker genes for genetic counselling. III. Proportion of informative families under linkage disequilibrium. Am J Hum Genet 1983;35: 592-610.

36 Farrer LA, Bonne-Tamir B, Frydman M. et al. Predicting genotypes at loci for autosomal recessive disorders using linked genetic markers: application to Wilson's disease. Hum Genet (in press).

37 Gusella JF, Gilliam TC, Tanzi RE, et al. Molecular genetics of Huntington's disease. Cold Spring Harbour Symp Quant Biol 1986;51:359-64.

${ }^{38}$ Carlock LR, Vo TD, DeHaven CR, Murray JC. An anonymous genomic clone that detects a frequent RFLP adjacent to the D4S10 (G8) marker and Huntington's disease. Nucleic Acids Res 1987;15:377.

39 Hodge SE, Spence MA, Crandall BF, Sparkes RF, Crist M, Tideman S. Huntington disease: linkage analysis with age-ofonset corrections. Am J Med Genet 1980;5:247-84.

4) Morton LA, Kidd KK. The effects of variable age-of-onset and diagnostic criteria on the estimates of linkage: an example using manic depressive illness and color blindness. Soc Biol 1980;27: $1-10$.

41 Heimbuch RC, Matthysse S, Kidd KK. Estimating age-of-onset distributions for disorders with variable onset. Am J Hum Genet 1980;32:564-74.

42 Cupples LA, Terrin NC, Myers RH, D’Agostino RB. Using survival methods to estimate age at onset distributions for genetic disease with an application to Huntington's disease. Submitted. 
${ }^{43}$ Kaplan EL, Meier P. Nonparametric estimation from incomplete observations. J Am Stat Assoc 1958;53:457-81.

44 Farrer LA, Conneally PM. A genetic model for age at onset in Huntington disease. Am J Hum Genet 1985;37:350-7.

45 Newcombe RG. A life table for onset of Huntington's chorea. Ann Hum Genet 1981;45:375-85.

$46 \mathrm{Ott} \mathrm{J}$. Estimation of the recombination fraction in human pedigrees: efficient computation of the likelihood for human linkage studies. Am J Hum Genet 1974;26:588-97.

47 Hodge SE, Morton LA, Tideman S, Kidd KK, Spence MA. Age-of-onset correction available for linkage analysis (LIPED). Am J Hum Genet 1979;31:761-2.

${ }^{48}$ Lathrop GM, Lalouel JM, Julier C, Ott J. Multilocus linkage analysis in humans: detection of linkage and estimation of recombination. Am J Hum Genet 1985;37:482-98.

49 Lathrop GM, Hooper AB, Huntsman JW, Ward RH. Evaluating pedigree data. $I$. The estimation of pedigree error in the presence of marker mistyping. Am J Hum Genet 1983;35: 241-62.

50 Jeffreys AJ, Brookfield JFY, Semeonoff R. Positive identification of an immigration test-case using human DNA fingerprints. Nature 1985;317:818-9.
51 Wexler NS, Young AB, Tanzi RE, et al. Homozygotes for Huntington's disease. Nature 1987;326:194-7.

52 Conneally PM. Huntington's disease: genetics and epidemiology. Am J Hum Genet 1984;36:506-26.

53 Folstein SE, Phillips JA, Meyers DA, et al. Huntington's disease: two families with differing clinical features show linkage to the G8 probe. Science 1985;229:776-9.

54 Hayden MR, Martin WRW, Stoessl AJ, et al. Positron emission tomography in the early diagnosis of Huntington's disease. Neurology (Minneap) 1986;36:888-94.

55 Young AB, Penny JB, Starosta-Rubinstein S, et al. Normal caudate glucose metabolism in persons at risk for Huntington disease. Arch Neurol 1987;44:254-7.

Correspondence and requests for reprints to $\operatorname{Dr} c$ Lindsay A Farrer, Department of Neurology, Bos- N ton University School of Medicine, Suite 1105, 720 Harrison Avenue, Boston, Massachusetts 02118, ㄱ USA. 